\title{
The PRAGMATIC FunCTIONS OF REPETITION IN TV DISCOURSE
}

\author{
GHALEB RABAB'AH
}

Alfaisal University, Saudi Arabia

grababah@alfaisal.edu

ALI FARHAN ABUSEILEEK

Al-albayt University, Jordan

alifarhan66@gmail.com

\begin{abstract}
Since repetition is a natural phenomenon used to perform various functions in interactional discourse, adopting a pragmatic analysis to the discourse of Dr. Phil and his guests on Dr. Phil's TV show, this study attempted to explore the pragmatic functions of such repetitions as used by English native speakers. The data were gathered from conversations between native speakers of English, and based on 7 full episodes of Dr. Phil's TV Show. The researchers watched, and studied these episodes on YouTube. The study revealed that one of the salient features of TV discourse is repetition, which is employed to perform a variety of language functions. Repetition was used to express emphasis, clarity, emotions, highlight the obvious, be questionable, express annoyance, persuasion, express surprise, give instructions, and as a filler in order to take time, when the speaker was searching for a proper word to say what would come next. The study concluded that these findings had significant implications for EFL/ESL teachers and the interlanguage development of EFL/ESL learners.
\end{abstract}

Key words: TV discourse, media, self-repetition, repair, repetition functions, communication strategies

\section{Introduction}

The present research assumes that native English speakers as represented by Dr. Phil and his guests use a range of communication strategies or devices to achieve their goals, among which is self-repetition. Therefore, the present research adopts a pragmatic analysis to the discourse of Dr. Phil, the host, and his guests on Dr. Phil TV talk show. More specifically, the study looks at the pragmatic functions of repetition in TV discourse. Pragmatics is defined as the study of the intended meaning. According to Green (2008), pragmatics is:

understanding intentional human action. Thus, it involves the interpretation of acts assumed to be undertaken in order to accomplish some purpose. The central notion $n$ Pragmatics must then include belief, intention (or goal), plan and act (p. 2). 
Similarly, Yule (1996:3) in his definition of pragmatics affirms that pragmatics is concerned with the study of meaning as communicated by a speaker (or writer) and interpreted between a listener (or a reader). Thus, pragmatics is the study of meaning in interactional context; that is, the meaning of a particular utterance can be constructed only when we place this utterance in its physical and linguistic contexts.

The study of repetition was repeatedly conducted within a broad framework of communication strategies (Genc, 2007). Communication strategies (CSs) are defined as strategies "used by an individual to overcome the crisis which occurs when language structures are inadequate to convey the individual thought" (Tarone, 1977:195). However, Faerch and Kasper (1983:36) viewed them as "potentially conscious plans for solving what to an individual presents itself as a problem in reaching a particular communicative goal."

The fact that CSs are used by both native and nonnative speakers has been supported by many researchers (e.g., Dornyei and Thurrell, 1991; Dornyei 1995; Kocoglu, 1997; Rabab'ah, 2001). Dornyei and Thurrell (1991) asserted that strategic competence (ability to use communication strategies) was "relevant to both L1 and L2, since communication breakdowns occur and must be overcome not only in a foreign language but in one's mother tongue as well." (p.17). Dornyei (1995) also described CSs as "various verbal and non-verbal means of dealing with difficulties and breakdowns that occur in everyday communication" (p. 55). Kocoglu (1997) concluded that native English speakers employed fewer communication strategies than did Turkish learners of English (e.g., self-repair, repetition and paraphrase). Similarly, Rababah (2001:3) found that "Arab learners used CSs in their native language, but when compared to the CSs used in their target language, these were fewer in terms of frequency and vary in terms of type." In another study investigating communication strategies used by Arabic as a Second Language (ASL) learners, Rabab'ah (2007) found that repetition, as a CS, was one of the most frequent strategies.

Not only was repetition given due attention in the taxonomies of communication strategies, but also its types and functions have been elaborated. Dörnyei \& Scott (1997) reported that "the L2 speaker's frequent need for more time to process and plan L2 speech than would be naturally available in fluent communication associated with strategies such as the use of fillers, hesitation devices, and self-repetitions" (p.183). Dornyei \& Thurrell (1994) concluded that repetition is a conversational strategy for dealing with communication 'trouble spots'. In their research on both native and nonnative speakers, Stuart \& Lynn (1995) found that non-native speakers resorted to repetition strategy more frequently than native speakers.

Ochs \& Schieffelin (1983) described repetition as one of the most misunderstood phenomena in psycholinguistics. Indubitably, repetition is a human, social activity, clearly part of our everyday conduct and behavior and not just a marker of a "disfluent" or "sloppy" speaker (Schegloff 1987). According to Tannen (1989), repetition is a phenomenon that occurs quite naturally in conversational speech. Similarly, Fillmore (1979) stated that the frequency of its occurrence allows us to question whether repetition, in fact, may not be "native- like". They may be too much, too little or even inappropriate use of repetition. Fillers are used to gain time in search for a vocabulary or a grammatical item. Shimanoff \& Brunak (1977) suggested that: 
Sophisticated speakers attempt to avoid absolute redundancy. For example, the speaker who uses 'let's say, let's suppose' will probably be perceived as a more eloquent communicator than the speaker who says 'let's let's let's suppose'” (p. 136).

Repetition in native speakers (NS) and non-native speakers' (NNS) speech, as a strategy of repair, has been intensively investigated (e.g., Schegloff et al., 1977; Tarone, 1980; Wong, 2000; Rieger, 2001; Haeyeon, 2002; Sawir, 2004; Cho, 2008; Laakso, 2010). Schegloff et al. (1977) describe the basic format of self-repair as initiation with a nonlexical initiator that is followed by the repairing segment (p. 376). These non-lexical initiators are comprised of cut-off, lengthening of sounds, and quasi-lexical fillers such as uh and um. Two of the four functions of self-repair suggested by Schegloff et al. (1977) are relevant to our study: word search and word replacement. Most of these functions involve the replacement of one lexical item by another, or in the case of repetitions, by the same lexical item, but the authors further subdivide these functions. According to Koshik \& Seo (2008), search for words during communication is used by both NS and NNS, and this is not due to the fact that they do not know or have not learned the words they are looking for, but they may have momentarily forgotten them. Therefore, they resort to repetition of a lexical item while searching for an appropriate word to fill the gap.

From this perspective, Rieger (2003) also investigated repetitions, as self-repair strategies, used in conversations in two related languages: English and German. Rieger (2003:51) asserts, "Repetitions -which are also called recycling - consist of the consecutive usage of the same quasi-lexical or lexical item or items. Her study revealed that her subjects repeat more pronoun-verb combinations, more personal pronouns, and more prepositions in English than in German, and they recycle more demonstrative pronouns in German than in English. These differences are explained by structural differences in English and German, demonstrating that the structure of a particular language shapes the repair strategies of language users because it creates opportunities for recycling. Rieger concluded that repetition as a self-repair strategy is an orderly phenomenon. Similarly, Cho (2008) examined repair strategies of elementary second language learners. The study revealed that partial repetition and request for repetition were among the most frequent strategies used.

\section{TV Show discourse studies}

Hess-Lu"ttich (2001) defined 'Show conversations' as conversations staged for show which address an audience, and they do not only include TV talk shows, but also dialogues on the theatrical stage. They are also prepared conversations that adopt basic communication rules, or they violate these rules in certain ways to achieve certain effects or goals. Although several studies have investigated the discourse of TV talk shows, these studies have been limited to the structure and the argumentative aspects of this discourse. For example, in examining the argumentation in two TV shows both in Germany and Switzerland, Hess-Lu"ttich (2007) investigated the discursive strategies in terms of empirical criteria (turn taking, speaking time, etc.), and the discursive strategies 
of the invited politicians in terms of qualitative data on the distribution of verbal power. The author concluded that:

... argumentation in talk shows serves to stage politics as symbolic action rather than to argue for better solutions to existing problems. The debate is presented as a controversy, contest, even as a battle, rather than as rational discussion and argumentation.” (p. 1369).

In studying the relationship between argumentation theory and discourse analysis, Rees (2007) concluded that both can benefit from each other. Bilal, H., Ahsan, H., Mujeeb, H. Gohar, S., Younis, Y, Awan, S. (2012) aimed to scrutinize the structures of two political talk shows of TV channels in Pakistan (Capital Talk and Lekin (but)) to make clear relationship between structure and meaning. Through the analysis, the researchers suggested that these TV talk shows used different tactics to "unravel the hidden truth and to project them to the public." and "gain a social power and the favor of public" (p.218). Thornborrow (2007) also examined the function of narrative discourse in the development of arguments in television talk shows. She demonstrated that TV talk arguments are "sequentially emergent from lay participants' narratives, and these narratives function to structure the production of opposing opinions and stances." Thornborrow discussed how stories are elicited, and "the problematising and evaluation of narrative actions by the host and other participants" (p. 1436). She argued that the articulation between narrative discourse and argument is one of the most important organizational features of TV talk show interaction.

However, it has been found that very limited research has investigated the communication strategies and devices used by TV show hosts. As far as the literature review is concerned, there is lack of studies that analyzed the discourse of TV shows from a pragmatic perspective (e.g., Aznárez-Mauleo'n, 2013). Aznárez-Mauleo'n noticed that in analyzing TV talk shows:

Scholars in media studies often focus on external parameters---features such as the topic, the participants, audience targets, production---adopting what we might call a macroperspective. This kind of description can be greatly enriched by an analysis of an essential component in most broadcast products, particularly in this kind of programme: the use of language (2013, p. 50)

Therefore, and based on that assumption, Aznárez-Mauleo'n (ibid) investigated the interactions between the TV talk host and guests. She found out that hosts use listenership devices, attention grabbing markers, repeating what the guest says, paraphrasing, and using compensatory strategies. She concluded that these strategies are related to "the hosts' role and their goals as managers of this kind of show."

\section{Discourse functions}

Some researchers have observed different functions of self-repetition in talk. For example, Kernan (1977:95) notes, "repetition recalls and reasserts the preceding token". Erickson (1984) finds that repeating oneself adds preciseness. Bublitz (1989) suggested that repetition is employed both to establish and maintain the continuous and smooth 
flow of talk, and also to state the participants' positions so as to help to ensure comprehension of what has been said and meant. Bublitz (1989) went on to describe other functions of repetition, which include facilitating comprehension since selfrepetition allows time for the speaker to plan what to say next or how to say it, and facilitates message comprehension on the part of the listener or second speaker. Bublitz added that self-repetition helps speakers to bridge gaps in conversation, and to state their position (agreement or disagreement) with respect to the other speaker's attitudes, decisions or opinions.

Repetition has been often handled 'under the rubric of communicative redundancy' (Brody 1986:255). According to Brody, "Repetition not only performs a variety of functions, but it may also be manifested in a number of different linguistic structures." (p. 255). The author argued for the multifunctionality of repetition. Norrick (1987:257) described four main functions of same-speaker repetition: semantically based, production-based, comprehension-based and interaction-based. Semantically based selfrepetition may be idiomatic or may reflect the iterative nature of the described object in an iconic manner. This kind of self-repetition is also realised through avoidance of ellipsis to be emphatic. Production-based self-repetition, takes place when a speaker wants to hold the floor and to gain planning time while searching for what to say next, or planning the rest of the move or turn, and to bridge an interruption. Comprehensionbased self-repetition can also be used to increase textual coherence in the ongoing talk, by the strategies of summarising, paragraphing and reintroducing a topic or a point of view. However, interaction-based self-repetition occurs when a speaker employs selfrepetition to ask and answer his own questions within the same turn. It can also take the form of repeat without any change, repeat with stress on a significant word of the original utterance and repeat with expansion.

Tannen (1989) identified several functions served by repetition in conversation, whose major role was to establish coherence and interpersonal involvement:

- participatory listenership, which shows that the person is listening and accepting what has been uttered;

- ratifying listenership, which occurs when the speaker incorporates the repeated phrase into their own narrative;

- humor;

- savouring through, which a speaker appreciates the humor in a situation;

- stalling, a function that allows time to interlocutor to find what to say next;

- expanding, which is the reformulation of an utterance followed by on-going talk; and

- repetition as participation, which helps develop the conversation.

(Tannen, 1989:47-52)

Tyler (1994:672) suggested that certain repetition patterns work as metadiscoursal markers, which signal to the listener how to interpret new information in an unfolding discourse. Similarly, Murata (1995) saw repetition as a culture-specific signal of conversational management, and considered immediate repetition of words and phrases as one feature of communicative behaviours. His study reveals that the use of immediate repetitions is closely related to the turn-taking system. McCarthy (1998:115) argued that 'repetition gives out important interactional signals' in spoken discourse, and this observation was based on the notion that self-repetition is a fundamental feature of a 
speaker's lexical competence, and constitutes a basic characteristic of vocabulary patterning in talk.

Holmes \& Stubbe (2003) observed that there are different functions of self-repetition in spoken discourse, and these include intensifying the force of the basic message and using repetition as a softener to manage and moderate the speech situation. Rieger (2003:1687) found that his German bilinguals repeat items for two main reasons: (1) to provide time for the planning of new utterances, that is, producing a 'filler' which compares to vocalized fillers, such as ah, er, erm, etc., and (2) to self-repair that is, attempting to correct a produced utterance.

Based on the assumption that CSs are used in times of difficulty, Bada (2010) showed two movies to non-native speakers of English (NNSE) and non-native speakers of French (NNSF). The participants' comments on these movies were analysed in order to observe prevalence, type and systematicity of repetition. The results of this study indicated that repetitions of grammatical and/or lexical elements were made irrespective of types or word class, phrase or sentence level. Most repeated elements among NNSE were observed to be verbs, pronouns and prepositions, and among NNSF, pronouns, determiners and verbs. Repetitions were made (1) as vocalized fillers, and (2) as selfrepairs.

In analyzing repetition and intensity, Bazzanella (2011) asserted that "Repetition, besides being a useful cognitive device (as a simplifying/clarifying device, a filler, and a support both for understanding and memorizing), an efficient text-building mechanism, and a widespread literacy and rhetorical device, is a powerful conversational and interactional resource." (p. 249). She concluded that repetition vary in its forms and functions, according to different contexts. In a study on repetition in social interaction, Hsieh (2011) pin-pointed that self-repeats can be used to emphasise function or when the listener does not catch up what was said in the previous turn. He also found that selfrepetition can be used to "double up the illocutionary force, i.e., to do emphasis or to do persuasion, by means of repeating the linguistic form" (p.163).

The literature review reveals that repetition is a natural phenomenon, which is used to accomplish various functions, that the majority of previous research on repetition focused on ESL learners, that little research focused on native English speakers, and that TV shows received little attention in CS research. The primary aim of this paper is, therefore, to explore the various functions of repetition as used by native English speakers on Dr. Phil's TV show. In other words, this study is an attempt to provide greater understanding of the functions or reasons of repetition in TV interaction. The main focus of this research is self-repetition, which is considered a pragmatic resource having various functions.

\section{The study}

\subsection{Research questions}

This study focuses on self-repetitions of native English speakers on Dr. Phil's TV show, and aims to seek answers to the following two research questions: 
1. Do native English speakers repeat language items in their interactions as manifested in Dr. Phil's TV show?

2. What are the main functions of these repetitions?

\subsection{Data}

The researchers of the present study gathered the data from conversations between native speakers of English in Dr. Phil, which was launched in 2002. Dr. Phil McGraw, perhaps the most well-known mental health professional in the world, is the host of Dr. Phil. The analysis was based on 7 full different episodes of this show: Fighting the System, the NWord Debate, Shocking Accusation, Parental Abuse, Young Women in Trouble, Teens Obsessed with Love, and the Kidnapping of Jaycee Lee. They were all watched and studied on YouTube. The researchers watched each episode several times, and transcribed all repetition occurrences, and classified them into their appropriate functional category. When one word was repeated in the same utterance, it was counted as a single instance of repetition; that is, not all repeated words were counted. To maximize their classification reliability, the researchers passed the categories along with their definition and the scripts to a panel of two EFL specialists, who were asked to check whether their classification was appropriate, and to provide recommendations for modifications. Their suggestions were taken into consideration.

\section{Results}

Concerning the first question in our study, which is related to whether native speakers of English repeat language items in their interactions as manifested on Dr. Phil's TV show, the results of the present study revealed that Dr. Phil, the host, employed self-repetition as a communication strategy that performs several functions. Since the study was limited to Dr. Phil TV show, it was noticed that both Dr. Phil and his guests used many repetitions (175 instances), which performed a wide range of functions. However, it was found that Dr. Phil resorted to repetition more than his guests did, 132 and 43 instances, respectively, which could be attributed to the fact that Dr. Phil was superior to the hosts. The hosts did not use as many repetitions as Dr. Phil did, because he possibly controls the interaction, and his main concern was eliciting all kinds of meanings to make his show successful. Table 1 shows the frequency of self-repetition in the seven episodes, which represent the data of the present study:

\begin{tabular}{|l|l|l|l|}
\hline Episode & Dr. Phil & Guests & Total \\
& & & \\
\hline Fighting the System & 17 & 5 & 22 \\
\hline Shocking Accusation & 18 & 5 & 23 \\
\hline The N-Words Debate & 19 & 7 & 26 \\
\hline The Kidnapping of Jaycee Lee & 20 & 5 & 25 \\
\hline Parental Abuse & 19 & 6 & 25 \\
\hline
\end{tabular}




\begin{tabular}{|l|l|l|l|}
\hline Episode & Dr. Phil & Guests & Total \\
& & & \\
\hline Young Women in Trouble & 21 & 7 & 28 \\
\hline Teens Obsessed with Love & 18 & 8 & 26 \\
\hline Total & $\mathbf{1 3 2}$ & $\mathbf{4 3}$ & $\mathbf{1 7 5}$ \\
\hline Percentage & 75.4 & 24.6 & $100 \%$ \\
\hline
\end{tabular}

Table 1: Frequencies and percentages of self-repetition in Dr. Phil

In answering question two, concerning the functions performed by repetitions, the study revealed that repetition was used by Dr. Phil and his guests not only to perform various functions, but it also was manifested in different linguistic structures. Repetition was employed for expressing emphasis, clarity, emotions, highlighting the obvious, being questionable, expressing annoyance, retaining a certain piece of information, persuasion, expressing surprise, giving instructions, and as a filler in order to take time, fill in the silence and hold the floor when the speaker is searching for proper words to say next. Another significant finding was that a single utterance in the interaction between Dr. Phil, the host, and his guests was used to perform a wide range of functions. For example, one utterance was used to express surprise, emphasis, and being questionable. In the following sections, these functions are discussed with examples taken from Dr. Phil's TV talk show.

\subsection{Emphasis}

Hsieh (2011:163) states, "Pragmatically speaking, repetition, both self-repeats and otherrepeats, can be used to double up the illocutionary force, i.e., to do emphasis or to do persuasion, by means of repeating the linguistic form." The data revealed that Dr. Phil and his guests employed self-repetition because they wanted to emphasise a particular word or phrase or sometimes highlight the obvious. Dr. Phil and his guests used repetitions, but it was noticed that Dr. Phil used them more frequently. This kind of repetition is manifested in the following scripts which are taken from different episodes:

1. I don't know that at this point...but I'm telling you what... I am going to find out and make no mistake. I am going to find out.

2. You own a hundred bucks....let's see here...I think you own a hundred bucks.

3. It's very important to sue these people... when they make a big deal, they have a right to go to court and have a right to have a trial by jury.

4. I failed the test. I have no idea how that happened. I don't know. I never touched her never never had touched her, never.

5. A: You will not see her. You will not see her anymore.

B: Oh really!!!

A: Unless you are supervised.

B: You are not going to get that?

A: Yes I am.

B: You are not going to get that? 


\section{A: Yea! I'll get supervised for sure.}

6. Hey you didn't come here as a slave...Your ancestors came as a slave.

As noticed in scripts 1-4, self-repetition was used for emphasis to reassure a fact to the listener, and focus his/her attention to that fact. Repeating "I am going to find out!", "You own a hundred bucks.", "They have the right to go to..." is a kind of emphasis. Although repetition was used to emphasize that he did not touch the girl (script 5), the guest repeated "never, never" to be more persuasive. In scripts 6 , the purpose of repetition was to stress what was said. Similarly, in script 6, Dr. Phil repeated "came as a slave" to emphasize a new fact.

\subsection{Emotional effect}

It was found that when Dr. Phil or his guests were emotionally affected, they resorted to self-repetition, which was manifested in clarification requests, especially when a particular point or the message which has been said earlier by his/her interlocutor was not clear. Clarification was made by asking a question, which required the hearer to answer, but in some cases, due to the significance of the idea, and in order not to be skipped without being fully understood, Dr. Phil repeated his clarification requests more than once to clarify the unclear ideas or points because he was either irritated or surprised. As can be seen in script 8 , Dr. Phil seemed very irritated when he said "That seems crazy to me!" Thus, he repeated different utterances here. He repeated "Did you...?" with some kind of paraphrase or repair in saying "Did you make a threat? Did you say that?" He also repeated "What did you say?" Similarly, scripts 8 and 9 witness repetition of "Did you....?" several times, which demonstrates the fact that Dr. Phil was irritated, and puzzled. In script 7, Dr. Phil was irritated and upset; therefore, he repeated "There is a little girl" to gain the sympathy of the audience. In script 10 , on the other hand, repeating "Mexican" twice illustrated how the guest felt. In script 11, the speaker repeated what he said three times because of the significance of "black and blue" marks, which aimed to raise the emotions of people who would, in turn, sympathize with her. She wanted them to feel how she felt when she was beaten by the airport security officers.

7. And there's a little girl involved here that doesn't have the ability to protect herself, there's a little girl that stands in harm way if something going there.

8. This seems crazy to me! You have a bottle of contact solution. What did you say? Did you make a threat? Did you say that? What did you say?

9. Come on! That doesn't make any sense .... What happened? Did you .. did you ...did you get frustrated ...did you get irritated? Were they rude to you... what ...what happened?

10. A: I am over it...I am over it.

B: Over what? Being Mexican?!!!!

A: No, I'm Mexican. I'm in this great country...I was born here by blood Mexican

11. I had black and blue marks all over my body. When I went to neurologists, he said "I see hand print on your arm in black and blue". The officer's hand prints were on my arm black and blue. 


\subsection{Being questionable}

Repetition was also used when Dr. Phil and his guests did not have an answer to some issues or concerns. It was noticed that one instance of repetition may have two functions. For example, in scripts 8 and 9 above, Dr. Phil was both emotionally affected and questionable. In the following scripts (12-15), Dr. Phil was questionable, puzzled, irritated, and annoyed. He does not understand why things happen; he had no answer to some questions.

12. What is it that people don't get? Either white people, African American! What...what is that people don't get?

13. I'm talking about if you have ever experienced however disgusting that might have been to you? Have you experienced any arousal in connection with your daughter?

14. Dr. Phil: Is this little girl safe in your home?

Guest: I thought so.

Dr. Phil: Is this little girl safe in your home...step up here and be a mother step up here and be $a$ woman.

15. What about this Jackson incident? ...is that something that crosses the line? Is that something shouldn't have been said?

\subsection{Expressing annoyance}

The data revealed that repetition was used by both Dr. Phil and his guests to express annoyance and not feeling good regarding an action. Repetition in the following scripts (16-18) is employed for expressing emotional feelings including emphasis and annoyance. Repeating "get off me", "They touched my pee" and "She is a baby!" is an indication that the speaker is very annoyed and upset because of what they did.

16. I just kept saying get off me... get off me... get off me

17. Guest (A) mother: What happened?

Guest (B) child: They touched my pee-pee

Guest (A) mother: Yea?!

Guest (B) child: They touched my pee-pee

18. She is a baby, Jeremy! She is a baby, Jeremy! How could you do that to her?

\subsection{Persuasion}

Another important function of self-repetition found in the data was persuasion. In fact, persuasion can be traced in most of the repetition instances, especially in Dr. Phil's talk because he wanted to control his guests' distrust and to encourage them. Dr. Phil and his guests repeated in order to be persuasive to their audience. As shown in the following script, Dr. Phil repeated "I can help you" three times to convince his guest to tell the truth by showing a desire to help. In order to persuade Dr. Phil of his idea, the guest in the second script stressed the word "never" and repeated it four times. 
19. I want to know the truth. It's your chance to clear yourself if that what you want to do and if you need help, tell me now. I can help you now...you tell me. I can help you more than... I can help you. If I find out later you were lying.

20. I failed the test. I have no idea how that happened. I don't know. I never touched her never never had touched her, never.

\subsection{Expressing surprise}

In most of the episodes, repetition was also used to express surprise. In script 21, Dr. Phil also repeats "You say you have ...." three times, expressing surprise to stress a point. In scripts 22 and 23, Dr. Phil seems questionable and surprised. However, repeating 'shame on you!' in script 22 was used to express emphasis and annoyance.

21. You know that you have had a lot of emotional challenges in your life. You say you have a problem with rage, you say you have a problem with anxiety; you work in a nightly stressful situation; you have trouble with boundaries ... you got angry; you hit things.

22. Is it possible that your father pled guilty to fondling a child? Is it possible that he has done that with you?

23. What are you doing here?! What are you doing? This child is paying for all of these.... call the police, I can't put her down; let it go now. All of that in front the child! Shame on you! Shame on you!

\subsection{Giving instructions}

In giving instructions, speakers on Dr. Phil's TV show used repetition to give instruction with an emphatic function. In script 24 , for example, Dr. Phil repeated 'step up here and be...' for emphasis. When Dr. Phil saw the report in script 25, and what his guest used to do the homeless and desperate people, he ended the interview and asked people to stop the tape. Here, he repeated "Stop the tape!". Then he asked the guest to walk away and repeated "Walk". Dr. Phil was very angry, and he asked the security to take his guest because he considered what he did to people a crime.

24. Dr. Phil: step up here and be a mother step up here and be a woman.

25. Dr. Phil: Stop the tape. Stop the tape. Walk. I don't want to talk to you. Walk. Guest: Why not?

Dr. Phil: It is very despicable.

\subsection{As a filler}

Repetition was used as an attempt to plan in order to take time, fill in the silence and hold the floor when Dr. Phil and his guests were searching for proper words to say next. In scripts 26 and 27, Dr. Phil repeated the definite article "the" three times, and "she wasn't" in order to gain time to retrieve what to say next. In script 28 , one of his guests repeated "he had a" in order to plan and recall what he wanted to say. The presence of 
hesitation indicated that the speakers were just filling a gap to retrieve the next lexical item or structure.

26. And do you and many of the the er the st strategies...

27. When she came back she wasn't er she wasn't a mother.

28. This is the guy who years ago kidnapped sexually assaulted and kept a woman in a in a prison... he he had a er he had a container where the woman had to go in.

\section{Discussion and conclusion}

The analysis concludes that Dr. Phil and his guests repeated some words and phrases to perform a wide range of functions, using several linguistic forms. They resorted to repetition to emphasise a particular proposition, sympathise, express puzzlement, convey annoyance, persuade the audience, express surprise, give instructions, and use it as a filler to plan in order to take time, fill in the silence and hold the floor. However, it was found that Dr. Phil used self-repetition more frequently. These findings concur with Aznárez-Mauleo'n (2013), who uncovered that TV hosts and guests use strategies and devices to achieve their goals. These findings also are in line with the findings of previous research on repetition and self-repair (e.g., Kernan, 1977; Brody, 1986; Norrick, 1987; Bublitz, 1989; Tannen, 1989; Tyler, 1994; Murata, 1995; McCarthy, 1998; Fung, 2007; Bada, 2010; Lee, 2010; Hsieh, 2011; Bazzanella 2011).

The findings of this research also confirm that self-repetition is a natural phenomenon that exists in all human interactions of native or non-native speakers. This concurs with Fung's view that "Self-repetition is commonly found in spoken discourse, and it could be argued that it is an interactional necessity" (2007:224). However, Stuart \& Lynn (1995), Rieger (2003), Rababah (2001), and Rabab'ah (2007) found that nonnative speakers resorted to self-repetition strategies more frequently than native speakers. Moreover, Schegloff (1987) considered repetition part of our everyday conduct and behavior, and not just a marker of a "disfluent" or "sloppy" speaker.

Because these repetitions have a certain function in the talk, the present research revealed that most of them are meaningful. This lends support to McCarthy (1998) that repetition has important interactional functions and meanings. Contrary to nonnative speakers, most repetitions done by native speakers as manifested in the present study, are meaningful and have significant functions in social interaction. One of the major characteristics of nonnative speakers' repeats is redundancy; in most cases, they repeat to gain time to retrieve an appropriate lexical or structural item (Shimanoff and Brunak, 1977; Fillmore, 1979).

The findings of this study are also in line with Dornyei \& Scott (1997), Author (2001), and Rabab'ah (2007) that repetition is a communication strategy used to gain time to plan for what comes next due to memory lapses. In this present research, it was found that a particular utterance performed a number of functions. That is, one utterance was not only used to express emphasis, but it was also used for clarification, persuasion or emotional effect.

The results indicated that self-repetition was used as a strategy of repair. This also supports Schegloff et al., (1977) and Rieger (2003) in that repetition of one or several lexical items is considered part of the self-repair organization when their function is to 
gain linguistic and/or cognitive planning time for the speaker. This study also confirms the view that self-repetition is a well-organised, orderly, and rule-governed phenomenon and not a chaotic aspect of spoken discourse (cf. Schegloff et al., 1977; Shriberg, 1994; Rieger, 2000).

These research findings have some implications for second/foreign language learners. Our study helps in putting together the communicative functions of repetition used by native speakers to meet their communicative goals in conversations. This study is also of significance in that recent studies have pointed out the importance of second language learners' use of repetition for conversational participation and language learning (Schegloff et al., 1977; Bazzanella, 2011) since repetition is a phenomenon of natural human interaction (Tannen, 1989; Rieger, 2003). This study, researching a wide range of repetitions, which vary in type and function, may help second or foreign language learners better understand the communicative functions and patterns of repetition, and know how to use them in real life situations. Teachers of English as a second/foreign language should also make their students aware of this phenomenon in natural spoken discourse.

McCarthy and Carter (1995:217) recommended a 'three I's' methodology to increase students' awareness of the nature of spoken discourse, and more specifically of repetition as a conversational discourse strategy. The 'three I's' stand for 'IllustrationInteraction-Induction'.

'Illustration means wherever possible examining real data which is presented in terms of choices of forms relative to context and use. Interaction means that learners are introduced to discourse-sensitive activities which focus on interpersonal uses of language and the negotiation of meanings...Induction takes the conscious-raising a stage further by encouraging learners to draw conclusions about the interpersonal functions of different lexical grammatical options, and to develop a capacity for noticing such features as they move through the different stages and cycles of language learning' (McCarthy and Carter, 1995:217).

Teachers may also adopt Walsh's methodology (2006), which recommended classroom recordings to identify different modes of discourse employed by teachers and students, in order to increase awareness of the importance of interaction and to maximize learning.

Finally, English language learners need to resort to self-repeats/self-repetition as a strategy while communicating in the target language because such repetitions give them time to retrieve what comes next, which, in turn, would help them in preventing communication breakdown. Instead of using fillers, such as $a h$, or $\mathrm{em}$, self-repetition, while having in mind the various functions of this strategy, may enable them to plan ahead of time for the next lexical or structural item, and be better communicators.

\section{References}

Aznárez-Mauleo'n, M. 2013. An approach to the host's discursive style in Spanish "testimony" talk shows. Journal of Pragmatics, 45: 50-73.

Bada, E. 2010. Repetitions as vocalized fillers and self-repairs in English and French interlanguages. Journal of Pragmatics, 42: 1680-1688. 
Bazzanella, C. 2011. Redundancy, repetition, and intensity in discourse. Language Sciences, 33: 243-254.

Bilal, H., Ahsan, H., Mujeeb, H. Gohar, S., Younis, Y, Awan, S. 2012. Critical discourse analysis of Political TV Talk Shows of Pakistani Media. Journal of International Linguistics, 4 (1): 203-219.

Brody, J. 1986. Repetition as a rhetorical and conversational device in Tojolabal (Mayan). International Journal of American Linguistics, 52 (3): 255-274.

Bublitz,W. 1989. Repetition in spoken discourse. Anglistentag 352-368.

Cho, Eun Hye 2008. An Examination of the Use of Repair Strategies of Elementary English as a Second Language (ESL) Students: By Class Type and Grade Levels. $\mathrm{PhD}$ Dissertation. Texas A \& M University.

Dornyei, Z. 1995. On the Teachability of Communication Strategies. TESOL QUARTERLY, 29: 55-85.

Dornyei, Z. and Thurrell, S. 1991. Strategic competence and how to teach it. ELT Journal, 45 (1): 16-23.

Dornyei, Zoltan, Scott, Mary L. 1997. Communication strategies in second language: definitions and taxonomies. Language Learning, 47: 173-210.

Dornyei, Z. and Thurrell, S. 1994. Teaching conversational skills intensively: Course content and rationale. ELT Journal, 48: 40-49.

Erickson, F. 1984. Rhetoric, anecdote, and rhapsody: Coherence strategies in a conversation among Black American adolescents. In Tannen D. (ed.) Coherence in Spoken and Written Discourse (pp. 91-102). Norwood, NJ: Ablex.

Færch, C., Kasper, G. 1983. Plans and strategies in foreign language communication. In Færch, C., Kasper, G. (eds.), Strategies in Interlanguage Communication (pp. 2044). Longman, London.

Fillmore, C. J. 1979. On fluency. In Fillmore, C. J., Kempler, D. \& Wang W. S. Y. (Eds.), Individual differences in language ability and language behavior (pp.85-102). New York: Academic Press.

Fung, L. 2007. The communicative role of self-repetition in a specialised corpus of business discourse. Language Awareness, 7 (3): 224-239.

Genç, B. 2007. An Analysis of Communication Strategies Employed By TurkishSpeakers of English. PhD Dissertation. Adana: University of Çukurova.

Green, G.M. 2008. Pragmatics and Natural Language Understanding, $2^{\text {nd }}$ ed. NY: Routledge.

Hess-Luttich, E., 2001. Textsorten gesprochener Sprache. In: Helbig, G., Lutz, H., Gert, Krumm H.-J. (Eds.), Deutsch als Fremdsprache. Ein internationales Handbuch [German as a Foreign Language] De Gruyter, Berlin, New York, pp. 280-300.

Hess-Luttich, E. 2007. (Pseudo-) Argumentation in TV-debates. Journal of Pragmatics, 39: $1360-1370$.

Holmes, J. and Stubbe, M. 2003. Power and Politeness in the Workplace. Harlow: Pearson Education.

Hsieh, F. 2011. Repetition in social interaction: A case study on Mandarin conversations. International Journal on Asian Language Processing, 19 (4):153-168.

Kernan, K.T. 1977. Semantic and expressive elaboration in children's narratives. In Ervin-Tripp, S. and Mitchell-Kernan, C. (eds.), Child Discourse (pp. 91-102). New York: Academic Press. 
Kim, H. 2002. The form and function of next-turn repetition in English conversation. Language Research, 38: 51-81.

Kocoglu, Z. 1997. The role of gender on communication strategy use. ERIC. Retrieved on March 23, 2010 from http://www.eric.ed.gov/PDFS/ED409725.pdf.

Koshik, I., Seo, M. 2008. Language learners' solutions to word (and other) searches. 2008 Conference of the National Communication Association. San Diego, CA.

Laakso, M. (2010). Cut-off or particle-devices for initiating self-repair in conversation. Journal of Pragmatics, 42: 1151-1171.

Lee, Jee Won 2010. Repetition of Personal Pronominal Forms in Mandarin and Construction of Stance in Interaction. PhD Dissertation. Los Angeles: University of California.

McCarthy, M. 1998. Spoken Language and Applied Linguistics. Cambridge: Cambridge University Press.

McCarthy, M. and Carter, R. 1995. Spoken grammar: What is it and how can we teach it? ELT Journal, 49: 207-218.

Murata, K. 1995. Repetitions: A cross-cultural study. World English, 14: 343-356.

Norrick, Neal, R. 1987. Functions of repetition in conversation. TEXT, 7 (3): 245-264.

Ochs, E., \& Schieffelin, B. 1983. Acquiring Conversational Competence. London: Routledge \& Kegan Paul.

Rabab'ah, G. 2001. An Investigation into the Strategic Competence of Arab Learners of English at Jordanian Universities. PhD Dissertation, University of Newcastle Upon Tyne/U.K.

Rabab'ah, G. and Bulut, D. 2007. Compensatory Strategies in Arabic as a Second Language. Poznan Studies in Contemporary Linguistics, Vol. 43, No. 2, pp. 83-106. Rees, M.A (2007). Discourse analysis and argumentation theory: The case of television talk. Journal of Pragmatics, 39: 1454-1463.

Rieger, C. L. 2003. Repetition as self-repair strategies in English and German conversations. Journal of Pragmatics, 35 (1): 47-69.

Rieger, C.L. 2000. Self-repair Strategies of English-German Bilinguals in Informal Conversations: The Role of Language, Gender and Proficiency. PhD Dissertation. University of Alberta

Sawir, E. 2004. Keeping up with native speakers: The many and positive roles of repetition in the conversations of EFL learners. Asian EFL Journal, 6: 1-32.

Schegloff, E.A., Jefferson, G., Sachs, H. 1977. The preference for self-correction in the organization of repair in conversation. Language, 53: 361-382.

Schegloff, E. 1987. Recycled turn beginnings: A precise mechanism in conversation's turn-taking organization. In Button, G. \& Lee, J. (eds.), Talk and Social Organisation, (pp.70-100). Clevedon, England: Multilingual Matters.

Shimanoff, S. and Brunak, J. 1977. Repairs in planned and unplanned discourse. In Keenan, E. and Benett, T. (eds), Discourse across Time and Space (pp. 123-167). Los Angeles: University of Southern California.

Shriberg, E.E. 1994. Preliminaries to a Theory of Speech Disfluencies. PhD Dissertation. Berkeley: University of California.

Stuart, S. \& Lynn, P. 1995. Development of communication strategies among foreign language learners. Mountain Interstate Foreign Language Review, 5: 122-127. 
Tannen, D. 1987. Repetition in conversation as spontaneous formulaicity. TEXT, 7: 215243.

Tannen, D. 1989. Talking Voices: Repetition, Dialogue, and Imagery in Conversational Discourse. Cambridge: Cambridge University Press.

Tarone, E. 1977. Conscious communication strategies in interlanguage. In Brown, H., Yorio, C., Crymes, R. (eds.), On TESOL'77. TESOL (pp. 194-203). Washington.

Tarone, E. 1980. Communication strategies, foreigner talk and repair in interlanguage. Language Learning, 30 (2): 417-431.

Thornborrow, J. 2007. Narrative, opinion and situated argument in talk show discourse. Journal of Pragmatics, 39: 1436-1453.

Tyler, A. 1994. The role of repetition in perceptions of discourse coherence. Journal of Pragmatics, 21: 671-688.

Walsh, S. 2006. Investigating Classroom Discourse. London: Routledge.

Wong, J. 2000. Repetition in conversation: A look at 'first and second sayings'. Research on Language and Social Interaction, 33: 407-424.

Yule, G. 1996. Pragmatics. Oxford: Oxford University Press.

\begin{abstract}
About the authors
Dr. Ghaleb Rabab'ah holds a PhD in Linguistics from the University of Newcastle upon Tyne, England. He is currently an Associate Professor of English at Alfaisal University, Saudi Arabia. His research interests include psycholinguistic aspects of second language, and language learning and teaching. He has published many research papers on linguistics, TESL, and CALL in international journals, such as Journal of Pragmatics, Poznan Studies in Contemporary Linguistics, and ITL-International Journal of Applied Linguistics.
\end{abstract}

Dr. Ali Farhan AbuSeileek is an Associate Professor at Al al-Bayt University. He has published papers and designed several CALL programs for EFL learners. His major research interest is CALL and its application in EFL teaching and testing, machine translation, and CALL program development. 